\title{
Changes in Instrumentally and Classically Conditioned Limb-Flexion Responses Following Inferior Olivary Lesions and Olivocerebellar Tractotomy in the Cat
}

\author{
Theodore J. Voneida,' Deborah Christie,, 2,a Rhonda Bogdanski, ${ }^{1}$ and Bohdan Chopko' \\ 'Department of Neurobiology, Northeastern Ohio Universities College of Medicine, Rootstown, Ohio 44272, and \\ 2Department of Experimental Psychology, Oxford, OX1 3UD, United Kingdom
}

Lesions were placed in various parts of the inferior olivary nucleus and olivocerebellar tract in an attempt to define further the role of the inferior olive in the performance of a conditioned limb-flexion response (LFR) in cats.

Thirty-two cats were trained to make an LFR using either classical or instrumental conditioning. The conditioned stimulus (CS) was a tone, and the unconditioned stimulus (US), a shock to the forelimb. Following training, lesions were placed in various parts of the inferior olivary nucleus in 20 animals (radio frequency lesions, 17; electrolytic lesions, 3 ). Midline section of the olivocerebellar tract was carried out in 12 animals. The degree of conditioned-response (CR) loss resulting from a given lesion was closely related to the precise locus of the lesion. Rostromedial olivary lesions, which included the spino- and cortico-olivary forelimb projection zones and the olivocerebellar projection area, resulted in varying degrees of CR loss (from partial to near total), deregulation of response latency, and a significant reduction of response amplitude. The CR deficit and degree of postoperative CR recovery were directly related to the extent of damage to this part of the rostromedial olive. Lesions restricted to the caudal olive or to caudal levels of the olivocerebellar tract resulted in no postoperative CR deficits. Animals with caudal lesions, however, showed more severe general motor deficits postoperatively than did those with rostromedial lesions and loss of the CR. Prolonged training of animals with the most complete CR deficits resulted in some relearning, but response patterns were typified by longlatency, low-amplitude CRs and a highly unstable response pattern.

In 1963, on the basis of an experimental analysis of instrumental limb-flexion conditioning in the cat, Voneida postulated that the cerebellum may represent a critical part of the neural circuitry underlying conditioned behavior. Numerous studies (Mc-

Received Jan. 29, 1990; revised Apr. 23, 1990; accepted June 25, 1990.

This work was supported by a Biomedical Research Grant from Northeastern Ohio Universities College of Medicine and by Grant 5R01 NS26053 from the National Institute of Neurological and Communicative Disorders and Stroke. D.C. was supported by a Fulbright-Hays Predoctoral Scholarship while in the Department of Neurobiology.

Correspondence should be addressed to Theodore J. Voneida, Ph.D., Chairman, Department of Neurobiology, Northeastern Ohio Universities College of Medicine, Rootstown, OH 44272.

a Present address: Department of Psychological Medicine, Hospitals for Sick Children, Great Ormond Street, London, UK.

Copyright (c) 1990 Society for Neuroscience $0270-6474 / 90 / 113583-11 \$ 03.00 / 0$
Cormick et al., 1981; McCormick and Thompson, 1983, 1984; Thompson et al., 1984; Yeo et al., 1985a,b; Thompson, 1986) have since demonstrated that the cerebellar cortex and certain of the deep nuclei (lateral interpositus/medial dentate) are critically involved in the development and retention of classically conditioned nictitating-membrane and limb-flexion responses (NMRs, LFRs). The results obtained from these studies are supportive of the Marr-Albus (Marr, 1969; Albus, 1971) hypothesis of cerebellar involvement in the classical conditioning of motor acts.

The cerebellar Purkinje cells are known to receive a major projection from the contralateral inferior olivary complex via the climbing fibers (Eccles et al., 1967; Matsushita and Ikeda, 1970; Armstrong et al., 1974; Brodal et al., 1975; Beitz, 1976; Courville et al., 1977; Kotchabhakdi et al., 1978; Groenewegen et al., 1979; Brodal and Kawamura, 1980; Montarolo et al., 1980). There is a high degree of topographic specificity in the olivocerebellar system (Brodal and Kawamura, 1980; Gellman et al., 1983, 1985; Gibson et al., 1983; Gibson and Gellman, 1987; Houk and Gibson, 1987). The climbing fiber input, with its single site of origin and specificity of termination, may be contrasted with the second major input to Purkinje cells, the mossy fibers, which arise from multiplc sourccs and influence widespread cerebellar cortical areas (Bloedel and Courville, 1981). Murphy et al. (1973), Rushmer et al. (1976), and Houk and Gibson (1987) have suggested that olivary cells function as somatic event detectors. Moreover, Bauswein et al. (1983), Thach (1967), and Andersson and Armstrong (1985) have shown that they are specifically attuned to somatic events that are "unsuspected" by the subject (e.g., unexpected removal of limb support during locomotion). Mossy fibers, on the other hand, transmit a wide variety of sensory inputs to the Purkinje cells, providing graded information about stimulus velocity, intensity, duration, and direction (Houk and Gibson, 1987). Marr (1969) proposed, on the basis of this convergence onto the Purkinje cell, that its regulation by climbing fibers might be subsumed by mossy fibers as learning proceeds. This idea was extended by Albus in 1971 to include classical conditioning of motor acts. Convergence onto a single Purkinje cell of the highly focused input from a single olivary cell and the broadly focused input from a very large number of mossy fibers (Eccles et al., 1967) led Houk and Gibson (1987) to propose a model of cerebellar function in which the cerebellum acts as an adjustable pattern generator. The cerebellar subunit, made up of a cerebellar nuclear cell together with a parasagittally aligned set of Purkinje cells that project onto it, constitutes the core of this model. Each subunit receives a highly focused climbing-fiber input from the inferior 
olive. Because climbing-fiber activity is known to be prominent when support for the limb is unexpectedly withdrawn and modest during unperturbed locomotion, Andersson and Armstrong (1985) and Houk and Gibson (1987) suggested that climbing fibers signal the occurrence of unexpected somatic events. The same subunit also receives the highly convergent input from large numbers of mossy fibers. The olivocerebellar system, presumed to mediate complex learned responses, led Ito (1984) to suggest that the climbing fibers act as "teachers" because the unexpected somatic events to which they respond appear to be appropriate signals for the shaping process typical of learned behavior. The recent conditioning studies of McCormick et al. (1985) and Yeo et al. (1986) are supportive of this idea, which is dependent on the specificity in the olivocerebellar projection system. They found that conditioned NMRs in the rabbit were disrupted by discrete lesions confined to the rostromedial inferior olivary complex, which projects to cerebellar lobule HVI. Lobule HVI and its projection to the interpositus nucleus are felt to constitute a necessary part of a proposed conditioned NMR "circuit" (McCormick and Thompson, 1983; Yeo et al., 1984).

This interpretation has recently been questioned by Welsh and Harvey (1989), who relate deficits in classically conditioned behavior following cerebellar lesions to a more general role of the cerebellum in the regulation of sensorimotor processes. They contend that conditioned-response (CR) deficits following interpositus lesions can be explained in terms of increased CR onset latency, decreased amplitude, and increased rise time of the response, rather than in terms of a memory deficit per se.

If the olivary/cerebellar complex does play a critical role in the learning and/or performance of an NMR in the rabbit, it is important to know whether this can be generalized to include other species and other conditioning paradigms. Although the LFR may not offer the same level of simplicity as the NMR, it is, nevertheless, a relatively simple response and thus provides a good model system for the study of learning and memory.

The present study was designed to examine the role of the inferior olivary nucleus in the performance of classically and instrumentally conditioned LFRs in the cat and to compare olivary-lesion effects with those reported by others (McCormick et al., 1985; Türker and Miles, 1986; Yeo et al., 1986) for the rabbit NMR. We are interested in the specificity and nature of the lesion effect on the conditioned limb response. Following the placement of lesions in various parts of the olivary complex or disconnection of the olive from the cerebellum by olivocerebellar tractotomy, trained subjects were tested for retention and/or relearning and for changes in latency and amplitude of the CR.

\section{Materials and Methods}

Subjects. Thirty-two adult male cats were used. They were housed in individual cages and maintained with free access to food and water throughout the duration of the experiment.

Apparatus. Animals were supported in a Plexiglas restraint through which the right forelimb was extended. The restraint was placed on an elevated stand in a sound-shielded enclosure. The auditory conditioned stimulus (CS) was a $500-\mathrm{msec}, 70-\mathrm{dB}, 1-\mathrm{kHz}$ tone delivered through a loudspeaker suspended $15 \mathrm{~cm}$ directly in front of the animal.

A small electric fan mounted in the back of the box provided ventilation and continuous background noise. A Velcro cuff with 2 Grass E5 gold-plated cup electrodes attached to the lower forelimb delivered the unconditioned stimulus (US), a 50-msec, 5-8-mA DC shock generated by a WPI Model 305 B stimulus isolator. The limb was also attached to a spring-loaded potentiometer connected to an Apple IIe computer. Response latency, amplitude, and a graphic analysis of each trial was displayed on a monitor, then printed out at the end of each session.

Procedure. All animals were routinely acclimated to the training apparatus over a period of $5 \mathrm{~d}$, after which they received 10 presentations of the CS only. The first day of training consisted of 5 paired CS/US trials. The number of paired trials was increased to 20 over the next 4 $\mathrm{d}$, after which daily sessions of 20 trials were given until a criterion level was achieved. Criterion was defined as $80 \%$ CRs for 2 of 3 consecutive $\mathrm{d}$, with a remaining score of not less than $75 \%$. In the classical paradigm, a 50 -msec US was presented $450 \mathrm{msec}$ after the CS onset, and they coterminated at $500 \mathrm{msec}$. The intertrial interval varied randomly between 30 and $60 \mathrm{sec}$. A limb flexion of $0.6 \mathrm{~mm}$ or more prior to the onset of the US was scored as a CR. In the instrumental paradigm, a limb flexion of the same amplitude before the US onset terminated the CS and prevented the onset of the US. Of those animals that received olivary lesions, 9 were trained on the classical paradigm and 11 on the instrumental. Six of the animals receiving tractotomies were trained on the classical paradigm and 6 on instrumental. Following criterion performance, training was terminated for $14 \mathrm{~d}$ to test for time-related losses. The animals were then tested for retention and trained for 5-10 d prior to surgery. To test for latent CRs that might occur during or after the US, animals were given 2 "probe" trials per training session. These consisted of a 450-msec CS, with a total CR observation period of 1000 msec. No US was given on these trials. A television tape of general behavior was made of each subject preoperatively and within 3-5 d postoperatively. This behavior included visual and tactile placing, running, jumping, and following and striking at moving targets. General motor activities were closely monitored and recorded on TV tape during the 2-week recovery period, after which training was resumed. Postoperative training was continued for a minimum of 750 trials and a maximum of 3 times the number of trials required to reach criterion preoperatively.

Surgery. All surgery was carried out under sterile procedures, with the aid of a surgical microscope. Animals were anesthetized with intramuscular ketamine hydrochloride (Ketaset; $24 \mathrm{mg} / \mathrm{kg}$ from a stock solution of $100 \mathrm{mg} / \mathrm{ml}$ ), mixed with Xylozine (Rompun; $1.4 \mathrm{mg} / \mathrm{kg}$ from a stock solution of $20 \mathrm{mg} / \mathrm{ml}$ ). Respiratory rate and reflexes (withdrawal, pinna, corneal) were carefully monitored throughout surgery, and maintenance doses of anesthetic were administered as needed. Intramuscular Combiotic $(600,000 \mathrm{U}$ penicillin/dihydrostreptomycin in aqueous suspension) was administered postoperatively.

Twelve animals received an olivocerebellar-tract section. The neck muscles were separated from the external occipital protuberance caudally to a level just below the foramen magnum. The dura overlying the fourth ventricle was cut longitudinally, and a thin knife was inserted in the midline, either manually guided or stereotaxically. The knife was advanced rostrally and caudally in an attempt to section the decussating olivocerebellar fibers. This procedure very frequently resulted in an abrupt respiratory arrest. Therefore, a tracheal tube was inserted before the animal was placed in the stereotaxic head holder, and a respirator was activated immediately prior to lesion placement. This remained on for variable periods up to $1 \mathrm{hr}$, or until it was determined that normal respiration had resumed. In spite of all attempts, 3 animals failed to regain voluntary respiration and expired as a result of this surgery.

Twenty animals received a direct lesion of the inferior olivary complex. Berman's Sterotaxic Atlas of the Cat Brain Stem (1968) was used to determine lesion sites of the left inferior olivary nucleus. Electrode entry was made from posterior at an angle $26-33^{\circ}$ from vertical, passing through the posterior lobe of the cerebellum. Olivary lesions were made electrolytically in 3 subjects ( $3 \mathrm{~mA}$ cathodal for $30 \mathrm{sec}$ ), and the remainder received radio-frequency lesions $\left(65^{\circ} \mathrm{C}\right.$ for $1 \mathrm{~min}$, using a $\mathrm{Ra}$ dionics Inc. RF generator).

Histology. Following postoperative observations, training, and testing, all animals were perfused through the heart with physiologic saline and $10 \%$ formalin. The brain was removed, fixed, and serially sectioned. Alternate sections were processed according to Weil (Berube et al., 1965) or Gallyas $(1971,1979)$ stains for myelin and Cresyl violet for cells prior to microscopic analysis and photographing of the lesion. Lesions were serially reconstructed with a microprojector.

\section{Results}

Animals trained using the instrumental paradigm required a mean number of 1389 trials to reach criterion, while classically 
trained animals required 550 trials $(t=3.5157, p=0.004)$. The distribution of CR onset latency (Fig. 1) for the 2 training paradigms was also significantly different. Classically trained animals gave most responses between 50 and $100 \mathrm{msec}$, whereas those trained instrumentally had a peak CR latency onset of $350-400 \operatorname{msec}\left(\chi^{2}=55.408\right.$, df $\left.-9, p<0.001\right)$.

Olivary lesions resulted in a response deficit in 8 animals ( 3 classical, 5 instrumental). Scores ranged from 30 to $60 \%$ for the first 5 postoperative sessions, at which time the scores of 3 animals ( 1 classical, 2 instrumental) continued to decline to 0 or near 0 , where they remained for a prolonged period. The remaining 5 animals, after an initial decline of CR scores similar to the above, showed a gradual, steady improvement to preoperative response levels (Fig. 2). Mean trials to criterion for these animals was 760 , and daily performance levels were highly unstable.

All animals had differing degrees of damage to the rostral $2 / 3$ of the left inferior olivary complex (Fig. 2). The lesion in those animals showing the most severe loss of the CR included ablation of the rostral olivary complex through the spinal forelimb afferent zone of the dorsal and medial accessory olive. In addition, the cortical forelimb afferent zone and the olivoccrcbellar forelimb projection zone was also destroyed in these animals. In those animals with an initial loss followed by gradual recovery, the rostral dorsal and medial accessory olive was only partially damaged, but in each case, chromatolytic cells were found in the most caudal parts of the "critical" zone.

None of the remaining 12 operated animals showed any postoperative reduction in CR scores. Six of these were found to have lesions caudal to the olive and were therefore excluded from further analysis. Five animals with caudal olivary lesions and 1 with minimal damage to the rostral olive maintained criterion performance of the CR for over 760 postoperative trials (Fig. 3). Lesions in this group spared the "critical" forelimb convergence zone in the rostromedial olive.

None of the animals that underwent olivocerebellar tractotomy showed any postoperative losses of the CR. All lesions in this group were found to be limitcd to the caudal half of the olivary complex, sparing those axons that arise in the olivocerebellar forelimb projection areas. The spino- and cortico-olivary projection zones were also spared, because, in addition to being limited to the caudal half of the olive, the lesions were restricted to midline or near-midline structures.

Television tapes were made of all subjects comparing preand postoperative visual and tactile placing, running, jumping, and following and accurate striking of targets. No postoperative changes were observed in those animals that showed the most severe losses of the CR (i.e., those with rostromedial olivary lesions). Animals with caudal olivary lesions and with tractotomies, however, all demonstrated variable, transient degrees of general motor disruption, including ataxia, loss of forelimb placing (visual and tactile), difficulty in following a moving target, and a high stepping gait. These behavior changes were most severe during the first 2 weeks following surgery, though some persisted for up to 1 month postoperatively, at which time their general behavior appeared normal.

We compared our olivary lesion reconstructions with the Brodal and Kawamura (1980) map (Fig. 4) showing olivary subdivisions and olivary connections. There is a direct relationship between the degree of CR loss and the extent of damage to that part of the rostromedial olive that receives cortical and spinal input and projects to the anteromedial cerebellar hemisphere.

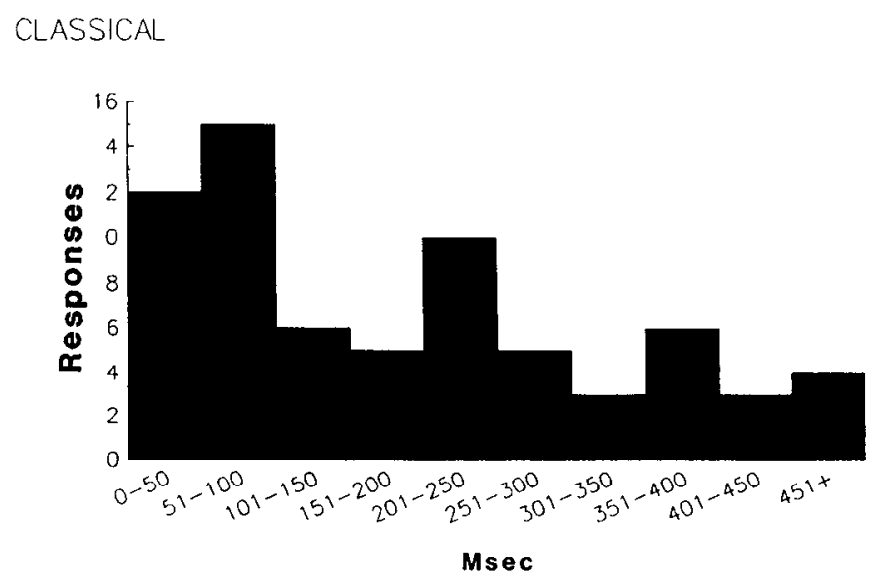

INSTRUMENTAL

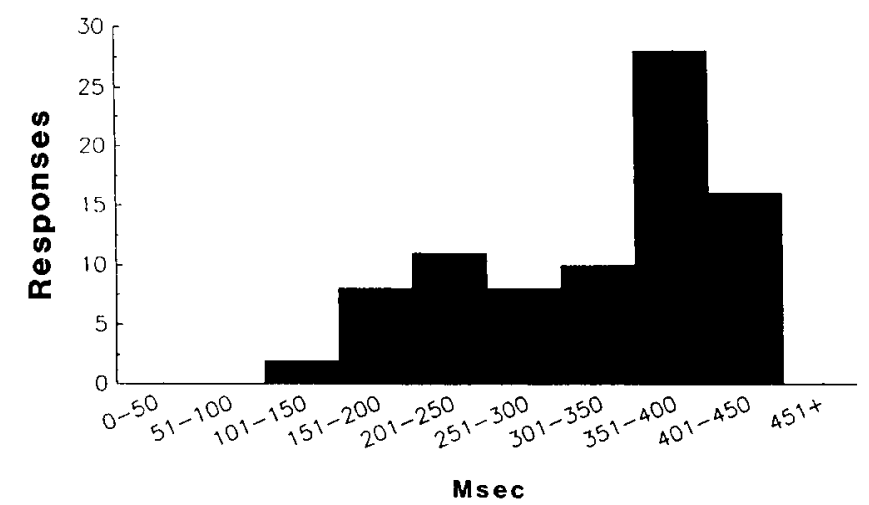

Figure 1. Frequency histograms of CR latencies recorded during the last 5 training $d$ prior to surgery. Latencies are expressed as the time from CS onset and are shown in $50-\mathrm{msec}$ 'windows' from 0 to $450 \mathrm{msec}$. The observation period extends to $1000 \mathrm{msec}$ for "probe" trials (2 per session), in which there was no US. $451+$ includes all responses from these trials.

The greatest losses occurred in those animals with complete or near-complete ablation of this "convergent zone." Animals with only partial damage to this area showed less severe CR deficits. Those animals that showed no postoperative loss of the CR were found to have posterolateral olivary lesions, with no involvement of the convergent zone.

Two of the animals that showed the most severe CR loss received extensive postoperative training. Figure 5 (individual scores per training session for each animal) shows that 1 (after an initial 4 sessions with scores of 20-75\%) dropped to near-0 levels for 900 trials ( $45 \mathrm{~d}$ ), then climbed to a near-criterion level after a total of 1700 trials, but was unable to maintain a stable level of performance. The other (after an initial 10 sessions with scores of $40-85 \%$ ) dropped to $0-20 \%$ levels for an extensive period, then achieved a near-criterion level after 2600 trials (130 d), though performance remained highly unstable, with scores fluctuating between 35 and $85 \%$.

\section{CR onset latency}

Frequency histograms were calculated to examine the distribution of CR onset latencics for animals that lost the CR for prolonged periods (Fig. 6) and for those that experienced an 
A
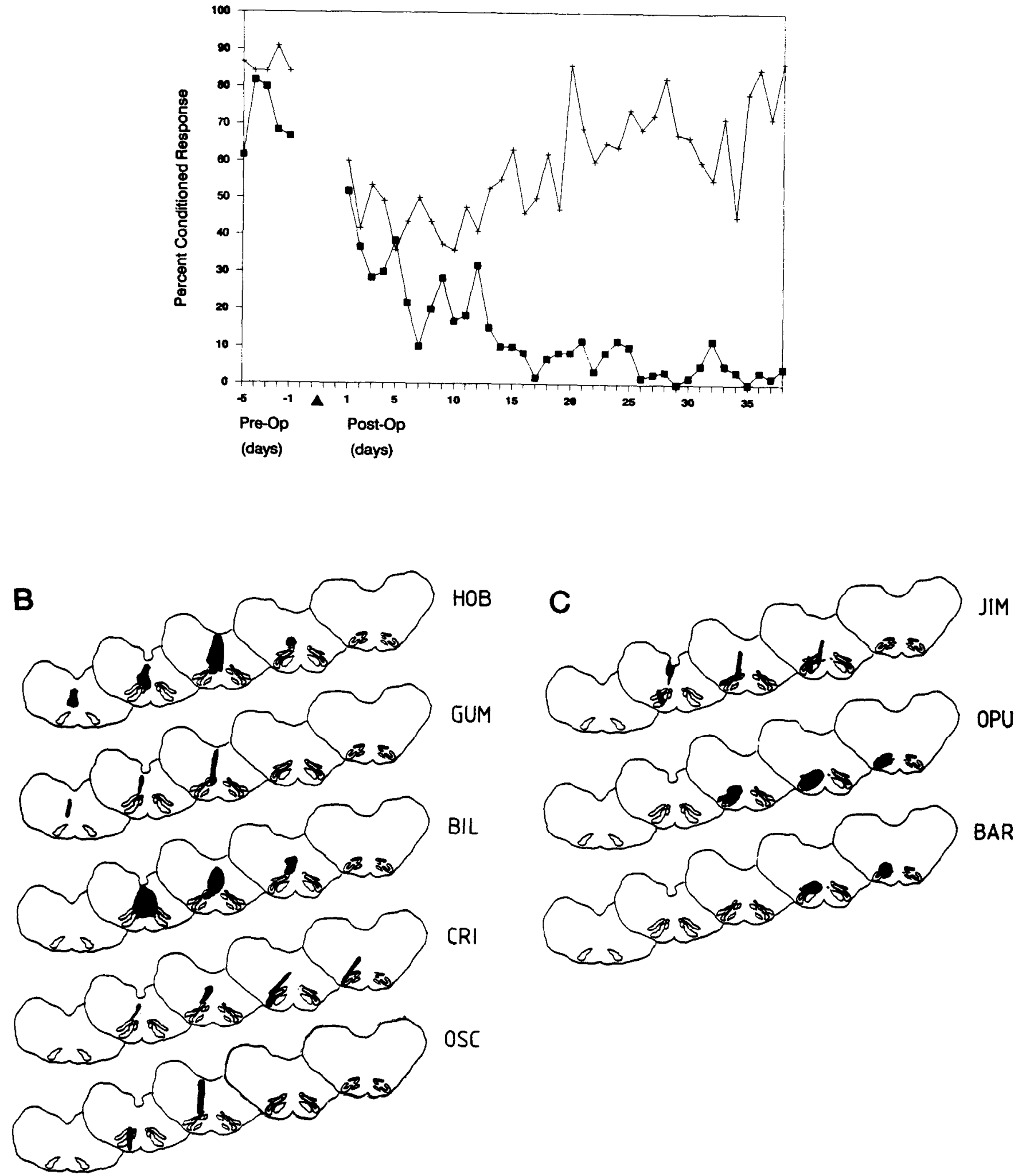

Figure 2. A, Mean percent CRs per training session, $5 \mathrm{~d}$ preoperatively and $38 \mathrm{~d}$ postoperatively for animals showing variable degrees of CR loss following olivary lesions. Those with the most severe deficit (squares) are compared with those showing an initial performance deficit followed by a gradual improvement to criterion (crosses). $B$. Individual lesion reconstructions of 5 animas, showing an initial performance deficit followed by over a prolonged period to criterion sevel $C$ Individual lon reconstructions of 5 animals, whose early postoperative scores gradually increased, gradually decreased to near 0 , where they remained for a prolonged reconstructions of 3 animals whose early, relatively high postoperative scores in black. 
A

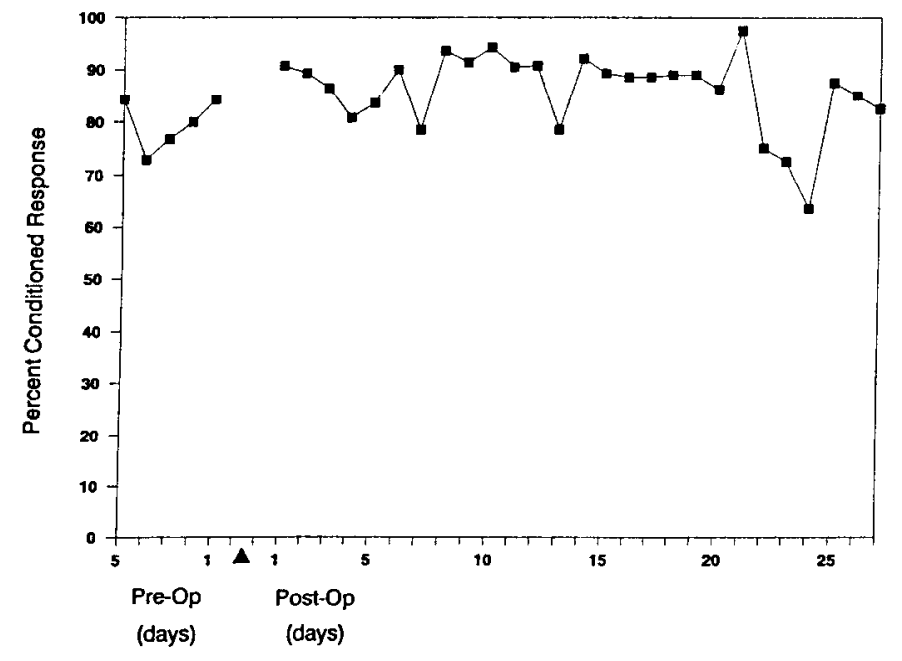

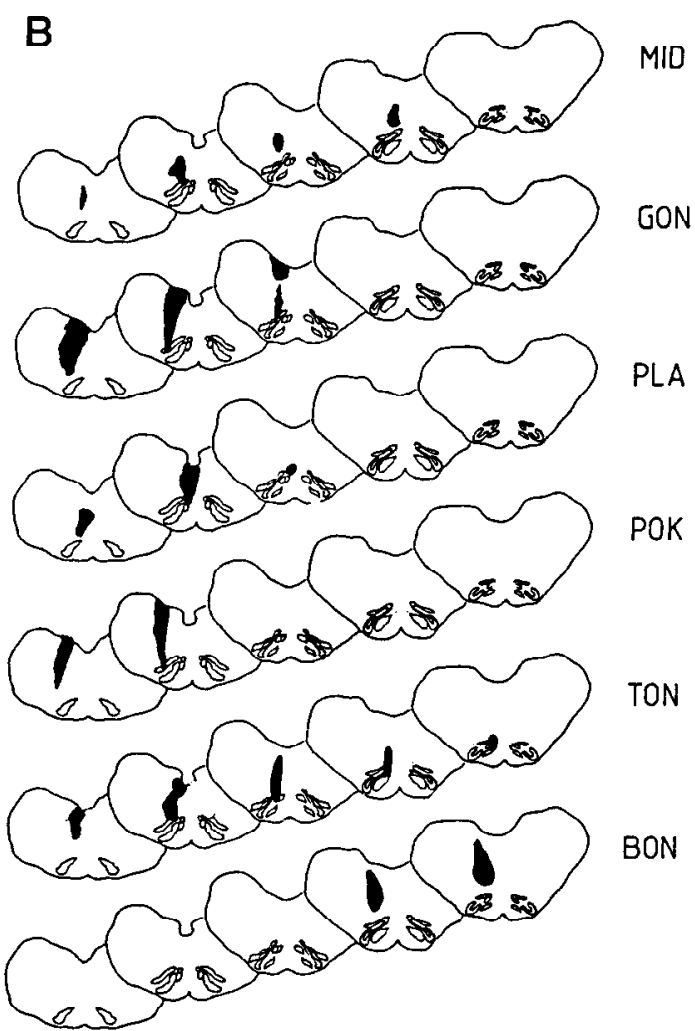

Figure 3. A, Mean percent CRs per training session, $5 \mathrm{~d}$ preoperatively and $27 \mathrm{~d}$ postoperatively for subjects with caudal olivary lesions. $B$, Individual lesion reconstructions of 6 animals in this group. Caudal is to the left.

initial loss followed by a gradual improvement to preoperative levels (Fig. 7).

Following lesions to the rostromedial inferior olivary complex, the CR onset-latency distribution of a classically trained animal changed significantly from a predominantly unimodal to a bimodal distribution (Fig. $6 A, B$ ). The peak response in the former was at $50-100 \mathrm{msec}$, with very few responses at $400-$ $450+\mathrm{msec}$; in the latter, small peaks occurred at $0-50 \mathrm{msec}$ and 50-100 msec, with a large increase in the number of responses made after $450 \mathrm{msec}$ (during the CS-alone "probe" trials). Pre- and postoperative distributions were significantly different $\left(\chi^{2}=22.48\right.$, df $\left.=9, p<0.01\right)$. Following lesions to the rostromedial inferior olivary complex, the CR onset-latency distribution of instrumentally trained animals also changed from a unimodal to a bimodal distribution (Fig. $6 C, D$ ). The peak response of the former was at $350-400 \mathrm{msec}$; in the latter, a small peak occurred at $50-100 \mathrm{msec}$, with a large increase in the number of responses made after $450 \mathrm{msec}$ (during the CSalone "probe" trials). Pre- and postoperative distributions were also significantly different $\left(\chi^{2}=51.475\right.$, df $\left.=9, p<0.0001\right)$. Thus, preoperative latency differences between classically and instrumentally trained subjects (classical, short latency; instrumental, long latency) disappeared during postoperative training (classical and instrumental, bimodal latencies).

The same analysis of pre- and postoperative latency distribution was performed on those animals showing an initial reduction in CR performance, followed by a gradual return to preoperative response levels. Although both classically and instrumentally trained animals showed a 50-100-msec increase in CR onset latency postoperatively, the distribution remained predominately unimodal (Fig. 7).
Finally, those animals that showed no postoperative CR loss (caudal olivary lesions/olivocerebellar tractotomies) also showed no significant postoperative latency changes. Mean pre- and postoperative latencies for these subjects were 258 and 241 msec, respectively.

Amplitude changes were also recorded following olivary lesions and tractotomies (Table 1). In general, as CR scores went down in those animals showing a loss of the CR, amplitudes also decreased. In the immediate postoperative period, when CR scores were at a relatively high level for this group, their amplitudes remained close to preoperative levels, with only slight decreases. As CR scores approached $0 \%$ their amplitudes decreased to half or less than half preoperative levels. Of the 2 animals in this group that received prolonged training and showed some degree of recovery, 1 showed no increase in amplitude over that observed during the low-score period. The other showed an increase in amplitude after prolonged training, but did not achieve preoperative levels. Those animals that showed no postoperative loss of the CR also showed no postoperative reduction in CR amplitude. Postoperative amplitudes of the latter were found to differ significantly from those showing performance deficits (Mann-Whitney $U_{4,8}=3, p=0.014$ ).

\section{Discussion}

This study may be viewed as an extension of those reported earlier by McCormick et al. (1985), Türker and Miles (1986), and Yeo et al. (1986), in which discrete lesions of the inferior olive and olivocerebellar tractotomy were found to abolish an auditory conditioned NMR in the rabbit and to prevent its reacquisition. Similar lesions before training were found to prevent the occurrence of learning. 
Caudal
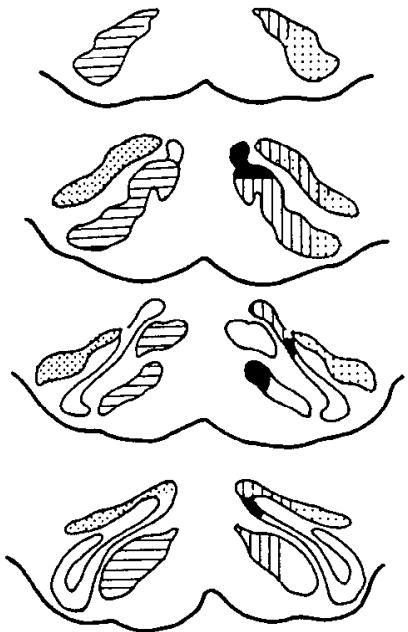

Rostral

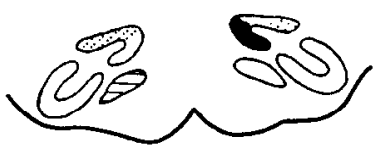

Sumpivisons of the Oivary Complex

Medal Accessory Olive

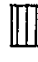

Olivocerebellar projection to media IIT] anterior cerebellar hemisphere

Dorsal Accessory Olive

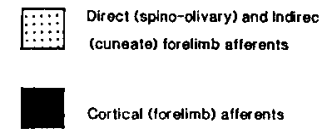

Figure 4. Enlarged scrics of sections through the olive based on Brodal and Kawamura (1980). The left side shows subdivisions of the olivary complex (hatching, medial accessory olive; stippling, dorsal accessory olive; open, principal olive). The right side shows relevant olivary efferents and afferents [hatching, olivocerebellar projection to the medial anterior cerebellar hemisphere; stippling, direct (spino-olivary) and indirect (cuneate) forelimb afferents; black, cortical (forelimb) afferents].

The highly specific climbing-fiber projection of olivary neurons onto the cerebellar Purkinje cells and numerous reports relating cerebellar cortical and deep nuclear lesions to conditioned learning make it logical to consider the inferior olive as an integral part of the circuitry related to learning and memory. The critical influence of the olivary/cerebellar complex on learned behavior is generally accepted, but there is disagreement as to the nature of this influence. Some hold that it is predominantly associative, with the inferior olive acting as a "teacher" of the cerebellum (Marr, 1969; Albus, 1971; Ito, 1984) by providing the US to the cerebellum (McCormick et al., 1985), which may itself represent a "locus of the memory trace" (Thompson, 1988). Others believe it to be regulatory, representing a more general control function of sensorimotor activity (Welsh and Harvey, 1989). Still others have suggested that the olive acts as a trigger for eliciting movements (Houk, 1979). A more recent proposal suggests that olivary input to the cerebellum acts to erase a previously established cerebellar representation of body position (Gibson and Gellman, 1987). Mossy-fiber input, arriving immediately after this "erasure," would provide the Purkinje cell with current, accurate information relative to body position.

Our results demonstrate that the degree of CR loss is directly related to the locus and/or extent of the lesion within the olivary complex. Thus, lesions outside the olivary forelimb areas were found to have little or no effect on the learned response, whereas the degree of loss resulting from lesions within the forelimb areas depended on the extent of input and output to and from extraolivary structures. The greatest losses resulted from damage to the rostral parts of the dorsal and medial accessory olivary nuclei, which receive convergent inputs from forelimb spinal cord and cerebral cortical areas (Oscarsson, 1968, 1969, 1980; Boesten and Voogd, 1975; Berkley and Hand, 1978; Brodal and Kawamura, 1980; Gellman et al., 1983; Molinari, 1984; Gibson and Gellman, 1987) and project onto cerebellar cortical forelimb areas and the nucleus interpositus anterior (Gibson et al., 1983). Lesions within the olivary complex that do not include all 3 of these areas have less profound and shorter-lasting effects on conditioned behavior. It therefore appears that olivary-lesion effects on conditioned learning, whether in the rabbit or the cat, instrumental or classical, are directly related to the highly specific spino- and cortico-olivary and to the olivocerebellar connectivity pattern. Although no amplitude or latency measurements were made of the unconditioned response in this study, they appeared to remain unaffected by the surgery.

The observation that rostromedial olivary lesions cause little or no change in general behavior, while caudal lesions and tractotomies result in ataxia, problems with visual and tactile placing, and accurate following of moving targets is similar to the findings of McCormick et al. (1985) in the rat. Wilson and Magoun (1945) have also described severe ataxia and decomposition of movement in the cat following inferior olivary lesions. The long-term severe ataxia and distinctive gait problems noted by Herken (1968), Desclin and Escubi (1974), and Llinas et al. (1975) following total olivary destruction resulting from intraperitoneal injections of 3-acetylpyridine in the rat were not observed in our animals. Transient ataxia and minor gait changes (characterized by increased limb flexion, but not as severe as the "mud walking" reported by Llinas et al.) were observed only in those animals with caudal olivary lesions and tractotomies. Desclin and Escubi (1974) did note that, in their animals, the caudal part of the main nucleus and dorsal accessory nucleus appeared to become impregnated earlier than the remainder of the olivary complex, though the entire olivary complex was ultimately destroyed by their injections. It seems reasonable to presume that differences between our animals and theirs are attributable to differences in lesion size and location, though species differences may also play a role.

As regards the nature of the CR loss, our findings in those subjects that suffered the most severe CR deficits are also in general agreement with those reported by McCormick and Thompson (1983), Steinmetz. et al. (1984), and McCormick et al. (1985), in which initial postoperative scores were commonly quite high, followed by a gradual decline in numbers of CRs over several training sessions to 0 or near- 0 levels. The similarity between this type of loss and extinction of a CR in normal animals, by withholding the US from presentation, lends support to the contention that the olive acts as a "teacher" of the cerebellum by providing it with information critically related to the US (Marr, 1969; Albus, 1971; Ito, 1984). It has thus been argued that withdrawal of the olivary input from the cerebellum is tantamount to withdrawal of the US, as observed in extinction paradigms. The fact that we have observed this effect in the cat LFR and that McCormick et al. (1985) have reported it in the rabbit NMR argues against species difference, though the "extinction" cffect was not observed by Yco ct al. (1986) following olivary lesions in NMR-conditioned rabbits. While a gradual 
A

JIM (Classical)

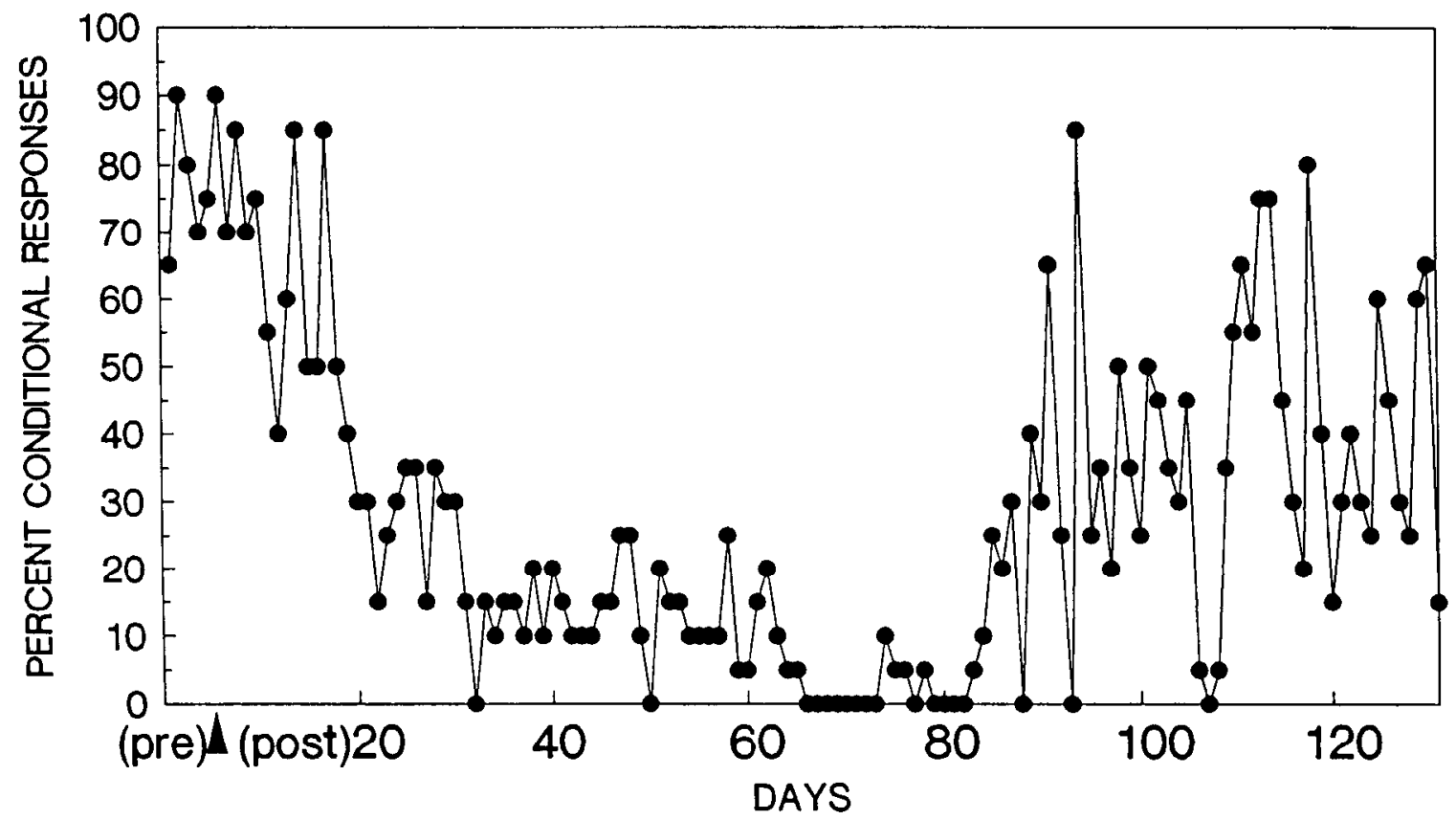

B

BARNEY (Instrumental)

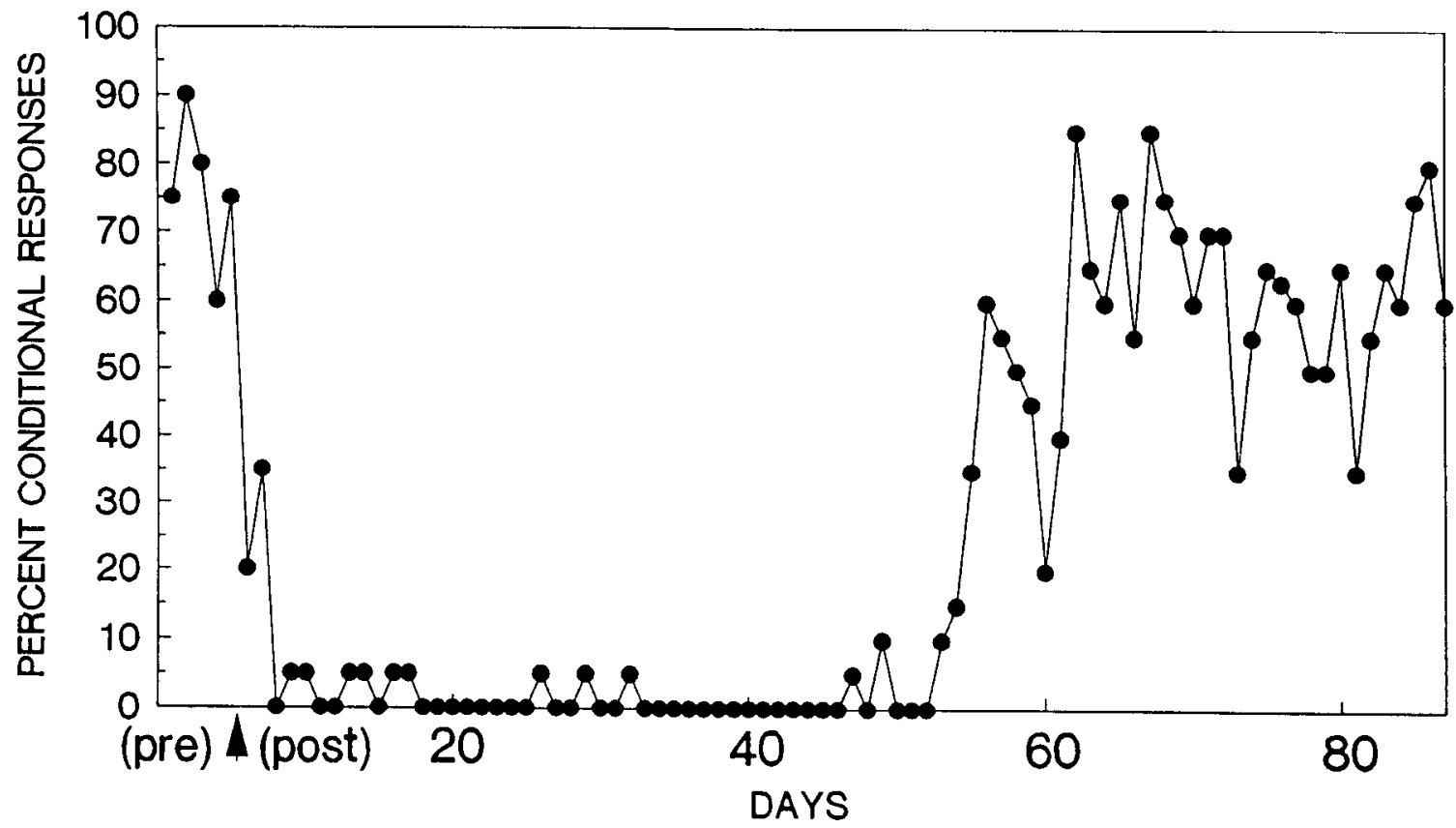

Figure 5. Mean percent CRs per training session, $3 \mathrm{~d}$ preoperatively and up to $131 \mathrm{~d}$ postoperatively for 2 animals $(A$, classical; $B$, instrumental) given extended postoperative training following rostromedial olivary lesions. 

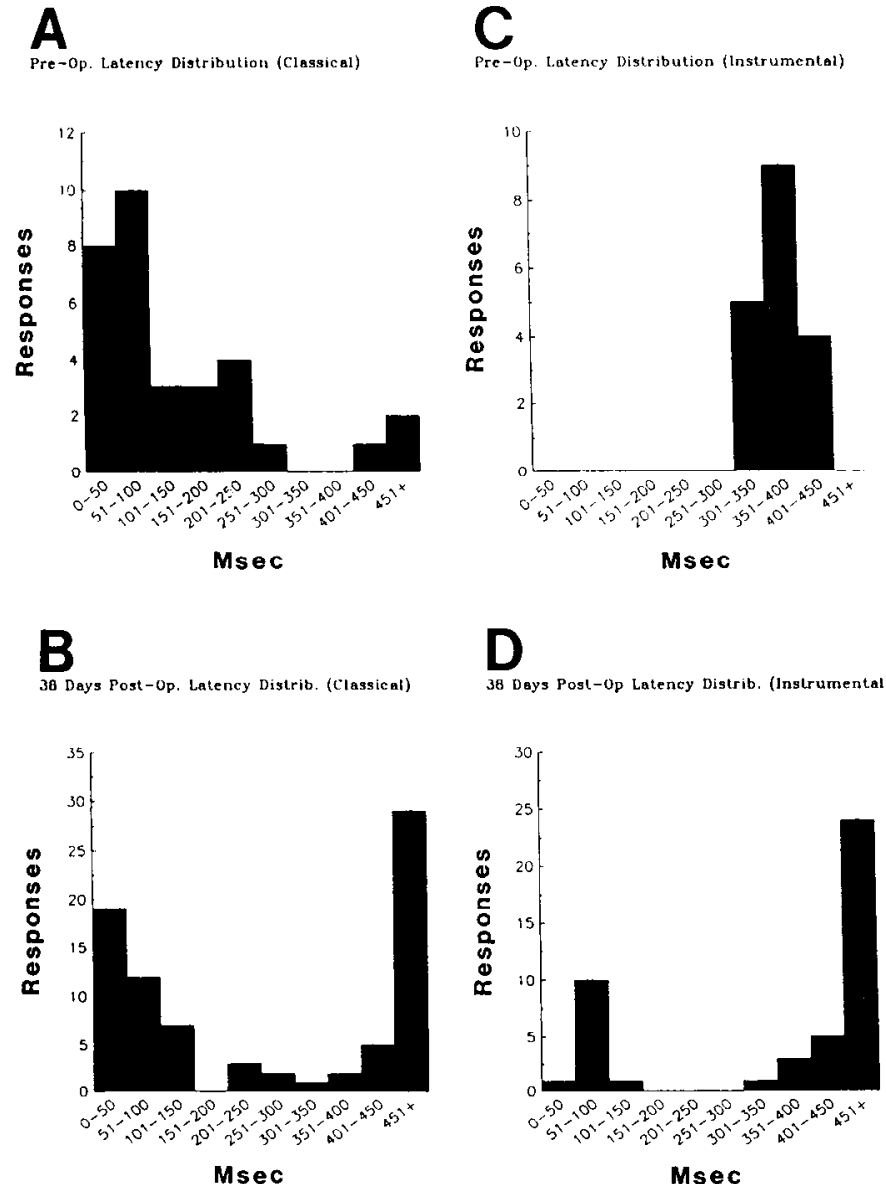

Figure 6. Frequency histograms showing distribution of pre- and postoperative latencies for animals that lost the $\mathrm{CR}$ following rostromedial lesions. $A$ and $B$, Classical paradigm. $C$ and $D$, Instrumental paradigm. Latencies are expressed as the time from CS onset and are expressed in $50-\mathrm{msec}$ 'windows' from 0 to $450 \mathrm{msec}$. The observation period extcnds to $1000 \mathrm{msec}$ for "probe" trials ( 2 per session), in which there was no US. $451+$ includes all responses from these trials. $A$ and $C$, Latencies recorded during the last $5 \mathrm{~d}$ prior to surgery. $B$ and $D$, Latencies recorded during $38 \mathrm{~d}$ postoperatively.

loss of the CR following rostral olivary lesions is consistent with the idea that the olive acts as cerebellar "teacher" by transmitting the US to it, as Gibson and Gellman (1987) point out, it is difficult to fit this concept into any scheme of sensory-motor integration.

The nature of the loss following olivary/olivocerebellar lesions is also related to the timing and amplitude of the response. Welsh and Harvey (1989) have reported that loss of the conditioned NMR following cerebellar interpositus lesions may in fact be due to an increase in response latency and rise time, and a decrease in response amplitude, rather than to disruption of a cerebellar locus for associative learning and memory. Our results also show latency and amplitude changes following olivary lesions, as might be predicted on the basis of Welsh and Harvey's findings, because there is such a close anatomic linkage between olivary and Purkinje cells. The nature of this latency change is best seen by comparing pre- versus postoperative latencies of classically and instrumentally trained subjects that showed a reduction in CR scores following olivary lesions. The preoperative latencies in classically trained animals are relatively short; that is, the CR occurs early during the CS-US
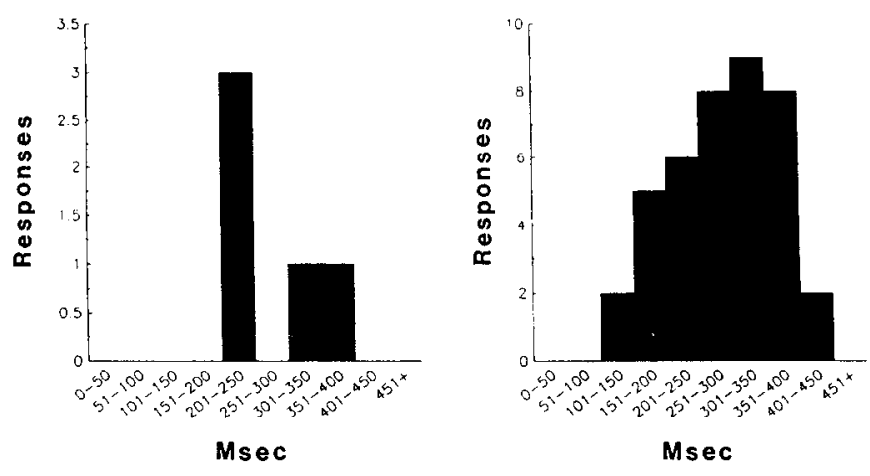

38 Days Post-Op. Latency Distrib. (Classical)

36 thys Post-0p Latency Distrib. (1nstrumental)
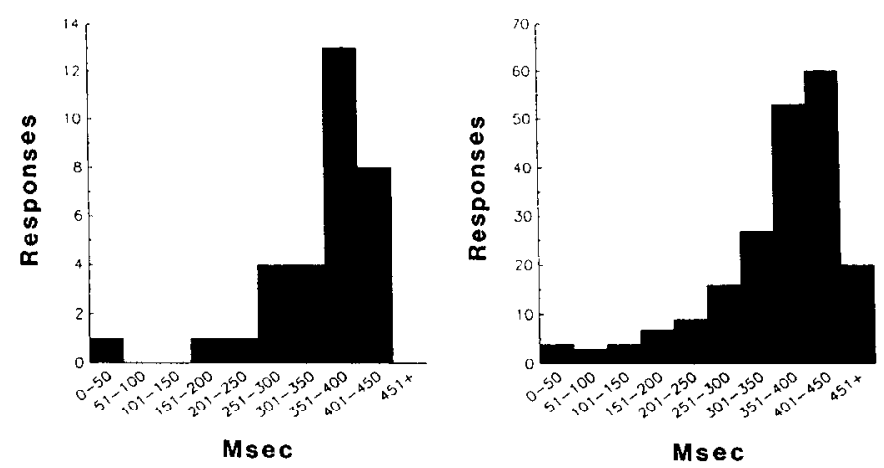

Figure 7. Frcquency histograms showing distribution of pre- and postoperative latencies for animals that showed an initial performance deficit followed by a gradual improvement to criterion. Latencies and pre- and postoperative observation periods are identical to those described in Figure 6.

interval (50-100 msec for most subjects). The preoperative latency of instrumentally trained animals is, by comparison, quite long, with the CR occurring late in the CS-US interval, at 300$400 \mathrm{msec}$. Effective olivary lesions in both classically and instrumentally trained animals resulted in deregulation of the CR, such that there was an initial spread of response latencies from a preoperative, unimodal distribution to a postoperative, bimodal distribution, with one cluster of latencies at $50-100 \mathrm{msec}$ and another at $400-450 \mathrm{msec}$. This bimodal distribution occurred during the "extinction" phase of postoperative training. During the "recovery" phase, there was a return toward a unimodal latency distribution, though the peak was still at longer latency than preoperatively. There appears to have been a deregulation of response such that, in instrumentally trained animals, inhibition of the CR (which normally occurs until just bcfore the US onset) is either greatly decreased, thus resulting in a decreased response latency, or greatly increased, causing responses to occur "too late" (i.e., the latency is increased beyond $450 \mathrm{msec}$ ). Classically trained animals show the same effect, with postoperative peaks occurring at $0-50 \mathrm{msec}$ and over $450 \mathrm{msec}$ (as recorded in probe trials). This effect is precisely what might be predicted in a deregulatory process. Olivary lesions thus appear to cause a severe disruption of the trained animals' ability to "time" their response: some latencies are longer and others are shorter than they were preoperatively. Preoperative latency differences between classically and instru- 
Table 1. Pre- and postoperative mean amplitudes for those subjects showing the most complete CR losses following olivary lesions and 2 representative subjects from the group showing no postoperative loss of the CR

\begin{tabular}{|c|c|c|c|c|}
\hline \multirow[b]{2}{*}{ Subject } & \multirow[b]{2}{*}{$\begin{array}{l}\text { Preoperative } \\
\text { mean }\end{array}$} & \multirow[b]{2}{*}{$\begin{array}{l}\text { Period prior to } \\
\text { CR loss }\end{array}$} & \multicolumn{2}{|l|}{ Postoperative means } \\
\hline & & & $\begin{array}{l}\text { During CR low-score } \\
\text { period }\end{array}$ & $\begin{array}{l}\text { During "recovery } \\
\text { phase" }\end{array}$ \\
\hline \multicolumn{5}{|c|}{ Most CR loss } \\
\hline $\mathrm{Jm}$ & 3.69 & 3.06 (240 trials) & $1.59(1320$ trials $)$ & $1.59(1320$ trials $)$ \\
\hline Op & 1.63 & $1.08(120$ trials $)$ & 0.77 (380 trials) & - \\
\hline $\mathrm{Bn}$ & 1.51 & 1.35 (80 trials) & 0.03 (780 trials) & 1.27 (1280 trials) \\
\hline \multicolumn{5}{|c|}{ No CR loss } \\
\hline $\mathrm{Mn}$ & 1.57 & 1.56 (60 trials) & - & - \\
\hline $\mathrm{Oc}$ & 0.35 & 0.37 (60 trials) & - & - \\
\hline
\end{tabular}

Mean amplitudes for subjects that lost the response are shown during the preoperative period (column 2); early postoperative period, prior to CR loss (column 3); the period when CR scores remained at the near-0 level (column 4); and (for 2 animals) during the period when CR scores began to increase (column 5). Amplitudes for subjects that did not lose the response remained at preoperative levels throughout their entire postoperative period of training.

mentally trained animals disappear. This response deregulation lends support to the findings of Colin et al. (1980), Benedetti et al. (1984), and Montarolo et al. (1982) in which inferior olivary lesions in the rat resulted in severe deregulation of Purkinje cell activity. The deregulation is thought to result from removal of a tonic regulatory influence exerted by the olive on Purkinje cells, causing a significant increase in the rate of simple-spike activity in the latter following olivary lesions.

The increase in response latency following disruptive olivary lesions is accompanied by a concomitant decrease in response amplitude. Again, the close anatomic relationship between olivary and Purkinje cells probably accounts for the similarity between our findings and those of Welsh and Harvey (1989) following cerebellar lesions in the rabbit. Fanardjian (1961) also observed an increase in latency and decrease in amplitude of LFRs in the dog following cerebellectomy, though his animals were not found to lose the CR. The precise cause of this reduced amplitude is unclear, but it is reasonable to assume that the deregulation of Purkinje cell activity reported by Benedetti et al. (1984), Colin et al. (1980), and Montarolo et al. (1982) following olivary lesions in the rat may also affect response amplitude.

Prolonged training (2-3 times the number of trials initially required to achieve criterion performance level) in 2 animals with near-total loss of the CR after rostromedial olivary lesions resulted in a recovery of the CR to near criterion levels. One explanation of this effect might relate to the findings of Benedetti et al. (1984), who showed that the Purkinje cell simple-spike activity, which greatly increases after olivary lesions (Colin et al., 1980; Montarolo et al., 1982), slowly decreases to normal levels over a period of about 1 month. If the CR impairment is due to deregulation of Purkinje cell activity as a result of the loss of olivary input, it is possible that when Purkinje cell activity returns to normal or near-normal levels, this will be accompanied by a concurrent increase in CR scores and amplitudes and a decrease in response latencies. It would be interesting to know whether these changes would also be seen in the absence of training during a 1 -month postoperative period. We did not test for this possibility, because our animals were given a 2-week postoperative recovery period. The question remains, why does recovery (of simple-spike activity and CR performance) occur? Benedetti et al. (1984) have also shown that complex-spike ac- tivity (climbing fibers), which is abolished or greatly reduced if measured 4-10 d following inferior olivary lesions in rats, increases significantly if a $2-3$ month recovery period is allowed. The number of surviving olivary cells was the same in both groups of animals, so they concluded that considerable sprouting must have taken place in the olivocerebellar fibers, and that the new fibers gave rise to functional synapses, thus increasing by 5-10 times the spatial domain of each remaining inferior olivary cell. Further studies are needed to determine if sprouting occurs in the cat olivocerebellar system following olivary lesions and if this can be correlated with recovery of CR latencies.

The results obtained in the present study, taken together with those reported by numerous others, make it abundantly clear that specific lesions in the olivary/cerebellar complex result in a profound disruption of the conditioned NMR and LFR in rabbits and cats. An outstanding question remains: namely, are the performance deficits resulting from such lesions due to the disruption of an associative network located within the cerebellum, as suggested by Thompson and co-workers (see Thompson, 1988 review), or do they represent a more generalized effect related to latency and amplitude changes as reported by Welsh and Harvey (1989) following cerebellar lesions and by ourselves following olivary lesions? A possible reconciliation of the question may be found in Houk's (1989) cooperative-control model of sensory-motor processing. This model offers an interpretation that incorporates most of the above suggestions related to learning losses and recovery following cerebellar and cerebellar-related brain-stem lesions. Briefly described, the model interprets the delay and weakening of learned responses (as compared to their total loss) following cerebellar lesions as a deficit in the learning of motor programs, because the storage of these programs represents the main function of learning mechanisms in the cerebellar cortex. Associative processes, Houk suggests, are represented by the learning of appropriate trigger signals for initiating these programs and are more likely to occur in the motor cortex, the red nucleus, or at other brain-stem sites along the corticocerebellar or rubrocerebellar loops. The deficits we have observed following rostromedial olivary lesions would, according to this model, result from the disruption of motor programs stored in the cerebellum. An interpretation of our data in terms of this model also fits with Marr's (1969) hypothesis, which proposed that the sole function of climbing-fiber synapses 
on Purkinje cells is to modify the properties of the parallel fiberPurkinje cell synapse. This modification, Marr suggested, is the basis for motor learning in the cerebellum.

Note added in proof. The following article appeared too late to include in this paper: Glickstein M, Yeo C (1990) The cerebellum and motor learning. J Cog Neurosci 2:69-80.

\section{References}

Albus JS (1971) A theory of cerebellar function. Math Biosci 10:2661.

Andersson G, Armstrong DM (1985) Climbing fiber input to b zone Purkinje cells during locomotor perturbation in the cat. Neurosci Lett [Suppl] 22:S27.

Armstrong DM, Harvey RJ, Schild RF (1974) Topographical localization in the olivo-cerebellar projection: an electrophysiological study in the cat. J Comp Neurol 154:287-302.

Bauswein E, Kolb FP, Leimeck B, Rubia FJ (1983) Simple and complex spike activity of cerebellar Purkinje cells during active and passive movements in the awake monkey. J Physiol (Lond) 339:379394.

Beitz AJ (1976) The topographical organization of the olivo-dentate and dentato-olivary pathways in the cat. Brain Res 115:311-317.

Benedetti F, Montarolo PG, Rabacchi S (1984) Inferior olive lesion induces long-lasting functional modification in the Purkinje cells. Exp Brain Res 55:368-371.

Berkley KJ, Hand PJ (1978) Projections to the inferior olive of the cat. II. Comparisons of input from the gracile, cuneate and the spinal trigeminal nuclei. J Comp Neurol 180:253-264.

Berman AL (1968) The brain stem of the cat. In: A cytoarchitectonic atlas with stereotaxic coordinates. Madison, WI: University of Wisconsin.

Berube GR, Powers MM, Clark G (1965) Iron hematoxylin chelates. 1. The Weil staining bath. Stain Technol 40:53-62.

Bloedel JR, Courville J (1981) Cerebellar afferent system. In: Handbook of physiology, Pt I, Vol II (Brooks VB, ed), pp 735-829. Bethesda, MD: Am Physiol Soc.

Boesten AJP, Voogd J (1975) Projections of the dorsal column nuclei and the spinal cord on the inferior olive in the cat. J Comp Neurol $141: 215-238$.

Brodal A, Kawamura K (1980) Olivocerebellar projection: a review. Advanc Anat Embryol Cell Biol 64:1-140.

Brodal A, Walberg F, Hoddevik GH (1975) The olivocerebellar projection in the cat studied with the method of retrograde axonal transport of horseradish peroxidase. J Comp Neurol 164:449-479.

Colin F, Manil J, Desclin JC (1980) The olivocerebellar system. I. Delayed and slow inhibitory effects: an overlooked salient feature of cerebellar climbing fibers. Brain Res 187:3-27.

Courville J, Augustine JR, Martell P (1977) Projections from the inferior olive to the cerebellar nuclei in the cat demonstrated by retrograde transport of horseradish peroxidase. Brain Res 130:405419.

Desclin JC, Escubi J (1974) Effects of 3-acetylpyridine on the central nervous system of the rat as demonstrated by silver methods. Brain Res 77:349-364.

Eccles JC, Ito M, Szentagothai J (1967) The cerebellum as a neuronal machine. New York: Springer.

Fanardjian VV (1961) The influence of cerebellar ablation on conditioned motor reflexes in dogs. J Higher Nerv Act 11:920-926.

Gallyas F (1971) A principle for silver staining tissue elements by physical development. Acta Morphol Acad Sci Hung 19:57-71.

Gallyas F (1979) Silver staining of myelin means of physical development. Neurol Res 1:203-209.

Gellman RS, Houk JC, Gibson AR (1983) Somatosensory properties of the inferior olive of the cat. J Comp Neurol 215:228-243.

Gellman RS, Gibson AR, Houk JC (1985) Inferior olivary neurons in the awake cat: detection of contact and passive body displacement. J Neurophysiol 54:40-60.

Gibson AR, Gellman RS (1987) Functional implications of inferior olivary response properties. In: Cerebellum and neuronal plasticity (Glickstein M, Yeo C, Stein J, eds), pp 119-140. New York: Plenum.

Gibson AR, Houk JC, Robinson FR (1983) Climbing fiber projection from physiologically identified areas of the cat dorsal accessory olive. Soc Neurosci Abstr 9:869.
Groenewegen JH, Voogd J, Freedman SL (1979) The parasagittal zonation within the olivocerebellar projection. I. Climbing fiber distribution in the intermediate and hemispheric parts of cat cerebellum. J Comp Neurol 183:551-602.

Herken H (1968) Functional disorders of the brain induced by synthesis of nucleotides containing 3-acetylpyridine. Z Klin Chem Klin Biochem 6:357-367.

Houk JC (1979) Motor control processes: new data concerning motoservo mechanism and a tentative model for SR processing. In: Posture and movement (Talbot RE, Humphrey DR, eds), pp 231241. New York: Raven.

Houk JC (1989) Cooperative control of limb movements by the motor cortex, brainstem and cerebellum. In: Models of brain function (Cotterill RMJ, ed), pp 309-325. Cambridge: Cambridge.

Houk JC, Gibson AR (1987) Sensorimotor processing through the cerebellum. In: New concepts in cerebellar neurobiology (King JS, Courville J, eds), pp 387-416. New York: Liss.

Ito $M$ (1984) The cerebellum and neural control. New York: Raven.

Kotchabhakdi M, Walberg F, Brodal A (1978) The olivocerebellar projection in the cat studied with the method of retrograde axonal transport of horseradish peroxidase. VII. The projection to lobulus simplex, crus I and crus II. J Comp Neurol 182:293-314.

Llinas R, Walton K, Hillman DE, Sotel L (1975) Inferior olive: its role in motor learning. Science 190:1230-1231.

Marr, D (1969) A theory of cerebellar cortex. J Physiol (Lond) 202: $437-470$.

Matsushita M, Ikeda M (1970) Olivary projections to the cerebellar nuclei in the cat. Exp Brain Res 10:488-500.

McCormick DA, Thompson RF (1983) Possible neuronal substrate of classical conditioning in the mammalian CNS: dentate and interpositus nuclei. Soc Neurosci Abstr 9:643.

McCormick DA, Thompson RF (1984) Cerebellum: essential involvement in the classically conditioned eyelid response. Science 223:296298.

McCormick DA, Lavond DG, Clark G $\Lambda$, Kettner RE, Rising CE, Thompson RF (1981) The engram found? Role of the cerebellum in classical conditioning of nictitating membrane and eyelid response. Bull Psychonom Soc 18:103-105.

McCormick DA, Steinmetz JE, Thompson RF (1985) Lesions of the inferior olivary complex cause extinction of the classically conditioned eyeblink response. Brain Kes 359:120-130.

Molinari HH (1984) Ascending somatosensory projections to the dorsal accessory olive: an anatomical study in cats. J Comp Neurol 223: 110-123.

Montarolo PG, Raschi F, Strata P (1980) On the origin of the climbing fibers to the cerebellar cortex. Pflugers Arch 383:137-142.

Montarolo PG, Palestini M, Strata P (1982) The inhibitory effect of the olivocerebellar input on the cerebellar Purkinje cells in the rat. $J$ Physiol (Lond) 332:187-202.

Murphy MG, O'Leary JL, Cornblath D (1973) Axoplasmic flow in cerebellar mossy and climbing fibers. Arch Neurol 28:118-123.

Oscarsson $O$ (1968) Termination and functional organization of the ventral spino-olivocerebellar path. J Physiol (Lond) 196:453-478.

Oscarsson $O$ (1969) Termination and functional organization of the dorsal spino-olivocerebellar path. J Physiol (Lond) 200:129-149.

Oscarsson $O(1980)$ Functional organization of olivary projection to the cerebellar anterior lobe. In: The inferior olivary nucleus: anatomy and physiology (Courville $\mathrm{J}$, de Montigny $\mathrm{C}$, Lamarre $\mathrm{Y}$, eds), pp 279-289. New York: Raven.

Polenchar BE, Patterson MM, LaVond DG, Thompson RF (1985) Cerebellar lesions abolish an avoidance response in rabbit. Behavioral and Neural Biol 44:221-227.

Rushmer DS, Roberts WJ, Augter GK (1976) Climbing fiber responses of cerebellar Purkinje cells to passive movement of the cat forepaw. Brain Res 106:1-20.

Steinmetz JE, McCormick DA, Bajer CA, Thompson RF (1984) Involvement of the inferior olive in classical conditioning of the rabbit eyelid. Soc Neurosci Abstr 10:122.

Thach WT (1967) Somatosensory receptive fields of single units in cat cerebellar cortex. J Neurophysiol 30:675-696.

Thompson RF (1986) The neurobiology of learning and memory. Science 233:941-947.

Thompson RF (1988) Localization of the essential memory trace circuit for a learned response. In: Brain structure, learning and memory (Davis JL, Wegman EJ, eds), pp 69-92. Boulder, CO: Westview. 
Thompson RF, Barchas JD, Clark GA, Donegan N, Kettner RE, Lavond DG, Madden J, Mauk MD, McCormick DA (1984) Neuronal substrates of associative learning in the mammalian brain. In: Primary ncural substrates of learning and behavioral change. (Alkon DL, Farley J, eds), pp 71-99. Princeton, NJ: Princeton UP.

Türker KS, Miles TS (1986) Climbing fiber lesions disrupt conditioning of the nictitating membrane response in the rabbit. Brain Res 363:376-378.

Voneida TJ (1963) Performance of a visual conditioned response in split-brain cats. Exp Neurol 8:493-504.

Welsh JP, Harvey JA (1989) Cerebellar lesions and the nictitating membrane reflex: performance deficits of the conditioned and unconditioned response. J Neurosci 9:299-311.

Wilson WC, Magoun HW (1945) The functional significance of the inferior olive in the cat. J Comp Neurol 83:69-77.
Yeo CH, Hardiman MJ, Glickstein M (1984) Discrete lesions of the cerebellar cortex abolish the classically conditioned nictitating response of the rabbit. Behav Brain Res 13:261-266.

Yeo CH, Hardiman MJ, Glickstein M (1985a) Classical conditioning of the nictitating membrane response of the rabbit: $I$. Lesions of the cerebellar nuclei. Exp Brain Res 60:87-98.

Yeo CH, Hardiman MJ, Glickstein M (1985b) Classical conditioning of the nictitating membrane response of the rabbit: II. Lesions of the cerebellar cortex. Exp Brain Res 60:99-113.

Yeo CH, Hardiman MJ, Glickstein M (1986) Classical conditioning of the nictitating membrane response of the rabbit: IV. Lesions of the inferior olive. Exp Brain Res 63:81-92. 